\title{
Desenvolvimento e qualidade do azevém no sub-bosque de angico-vermelho em sistema silvipastoril
}

\author{
Janine Pilau, Elvis Felipe Elli*, Maicon Nardino, Cleiton Korcelski, \\ Denise Schmidt, Braulio Otomar Caron
}

Universidade Federal de Santa Maria, RS, Brasil

*Autor correspondente, e-mail: elvisfelipeelli@yahoo.com

\section{Resumo}

O objetivo deste trabalho foi avaliar o desenvolvimento e qualidade do azevém no sub-bosque de angico-vermelho em sistema silvipastoril. $O$ delineamento experimental utilizado foi de blocos completos casualizados, em esquema fatorial $2 \times 6$, ou seja, dois sistemas de produção (pleno sol e silvipastoril) e seis cortes (15, 30, 45, 60, 75 e 90 dias após a emergência do azevém), com três repetições. Avaliou-se a interceptação de radiação solar fotossinteticamente ativa incidente, temperatura média do ar, massa de matéria seca, área foliar e teor de proteína bruta. De acordo com a análise de variância, a interação entre sistema de produção e corte demonstrou diferença significativa para a massa de matéria seca, já o teor de proteína bruta e área foliar demonstraram diferença apenas em função dos cortes realizados. O desenvolvimento do azevém é influenciado pelo sombreamento, quando cultivado no sub-bosque de angico-vermelho emsistema silvipastoril. O sombreamentoprovocado pelo angico-vermelho reduz o rendimento da massa de matéria seca do azevém, porém essa redução não limita o uso da espécie para compor um sistema silvipastoril. O teor de proteína bruta e a área foliardo azevém não são influenciados pela restrição luminosa.

Palavras-chave: Lolium multiflorum, Parapiptadenia rigida,sombreamento, radiação solar

\section{Development and quality of ryegrass in an understorey of angico-vermelho in a silvopastoral system}

\begin{abstract}
The aim of this study was to evaluate the development and quality of ryegrass in an understorey of angico-vermelho in a silvopastoral system. The experimental design was a complete randomized block, with a $2 \times 6$ factorial, being two systems of production (full sunlight and silvopastoral) and six times of harvest $(15,30,45,60,75$ and 90 days after ryegrass emergence), with three replications. The interception of the photosynthetically active solar radiation, average air temperature, dry matter, leaf area and protein content were evaluated. According to the analysis of variance, the interaction between production system and time of harvest resulted in significant differences for dry matter and the protein content and leaf area resulted in differences only according to the harvest time. The development of ryegrass is influenced by shading, when grown in this study conditions. The shade provided by angico-vermelho reduces the amount of ryegrass dry matter of ryegrass, but this reduction does not limit the use of the specie to compose a silvopastoral system. The total protein content and leaf area of ryegrass are not influenced by the light restriction.
\end{abstract}

Keywords: Lolium multiflorum, Parapiptadenia rigida, shading, solar radiation 


\section{Introdução}

A demanda crescente por alimentos, produtos florestais e bioenergia, além da necessidade de redução de desmatamento e da emissão de gases do efeito estufa, necessitam de alternativas que incentivem - desenvolvimento socioeconômico, sem comprometer a sustentabilidade dos recursos naturais. Neste contexto, os sistemas silvipastoris (integração floresta-pecuária, SSP), têm sido destacados como uma alternativa para a solução destes problemas (Balbino et al., 2011).

Além disso, os SSP podem reduzir os efeitos da erosão hídrica e manter elevado - teor de carbono orgânico do solo(Aguiar et al., 2010), uma vez que os componentes arbóreos promovem maior retenção de água em subsuperfície do solo e uma melhoria das condições de cultivo, possibilitando o desenvolvimento satisfatório de outras espécies cultivadas em sub-bosque (Wang et al., 2011; Yang et al., 2009). Dessa maneira os produtores rurais podem intensificar a utilização de suas propriedades, pois esses sistemas permitem a comercialização de mais de um produto em uma mesma área, além da amortização dos investimentos iniciais.

A escolha da espécie florestal, assim como a densidade e o espaçamento de plantio, são decisões importantes a serem tomadas para o sucesso na implantação do SSP. As interações entre a densidade arbórea com o crescimento e a qualidade da pastagem no sub-bosque sombreado garantem o sucesso dos SSP para produção de matéria seca forrageira (Barro et al., 2008) podendo também afetar o valor nutritivo do pasto em função da adaptação morfofisiológica (Paciullo et al., 2011).

Dentre as opções de forrageiras que podemserutilizadasparaformaçãodepastagens, o azevém anual (Lolium multiflorum) é uma das mais utilizadas por pecuaristas do Rio Grande do Sul, no período invernal, quando as espécies forrageiras nativas, base da alimentação dos rebanhos gaúchos, reduzem ou até paralisam o crescimento e desenvolvimento.Desse modo, se faz necessário avaliar as características de produção e qualidade nutritiva desta forrageira nos diferentes ambientes, para que se possa explorá-la ao máximo e de maneira adequada.

Frente ao intuito de viabilizar a inserção de novas espécies, tanto florestais, quanto forrageiras, para a utilização nestes sistemas como alternativa para o produtor rural, o objetivo deste trabalho foi avaliar o desenvolvimento do azevém no sub-bosque de angico-vermelho em sistema silvipastoril.

\section{Material e Métodos}

O estudo foi realizado na área experimental pertencente ao Laboratório de Agroclimatologia, vinculado à Universidade Federal de Santa Maria campus Frederico Westphalen - RS, com localização geográfica de $27^{\circ} 22^{\prime}$ S, 532 $25^{\prime} \mathrm{W}$ a $480 \mathrm{~m}$ de altitude. Segundo a classificação climática de Köppen, o clima da região é Cfa, ou seja, subtropical úmido com temperatura média anual de $19,1^{\circ} \mathrm{C}$, variando com máximas de $38^{\circ} \mathrm{C}$ e mínimas de $0^{\circ} \mathrm{C}$.

O solo da área experimental é classificado como Neossolo Litólico eutrófico típico pouco profundo (Cunha, 2011). Os valores das características químicas do solo foram: $\mathrm{pH}$ em água, 5,8; $\mathrm{P}$ disponível (Mehlich-I), 2,9 mg $\mathrm{dm}^{-3} ; \mathrm{Al}, 0,0 \mathrm{cmol}_{\mathrm{c}} \mathrm{dm}^{-3} ; \mathrm{K}, 82,5 \mathrm{mg} \mathrm{dm}-3 ; \mathrm{Ca}, 8,7$ $\mathrm{cmol}_{\mathrm{c}} \mathrm{dm}^{-3}$ e Mg, 2,8 $\mathrm{cmol}_{\mathrm{c}} \mathrm{dm}^{-3}$, determinados no Laboratório de Análise de Solo e Tecido Vegetal da Universidade Regional Integrada do Alto Uruguai e das Missões - URI, em Frederico westphalen - RS.

O delineamento experimental utilizado foi de bloco ao acaso, em esquema fatorial $2 \times 6$, ou seja, dois sistemas de produção (SSPe pleno sol, PS) e seis cortes $(15,30,45,60,75$ e 90 dias após a emergência do azevém),com três repetições.O angico-vermelho (Parapiptadenia rigida)foi implantado em setembro de 2007 , sendo distribuído em renques separados por 6 $\mathrm{m}$ e 1,5 m entre plantas, orientadas no sentido Leste-Oeste, totalizando uma densidade de 1.111 árvores por hectare. Cada unidade experimental apresentava uma área de $36 \mathrm{~m}^{2}$, tanto no SSP, quanto no pleno sol.

O azevém foi semeado em 05/06/2012, a lanço, em solo previamente revolvido e destorroado, com densidade de sementes de $40 \mathrm{~kg} \mathrm{ha}^{-1}$, valor corrigido de acordo com a pureza e germinação, sendo que após a 
semeadura as sementes foram incorporadas com uma gradagem.A adubação foi realizada conforme as recomendações para cultura (Comissão de Química e Fertilidade do Solo, 2004). Neste período as árvores de angicovermelho apresentavam diâmetros médios do colo (DC) e da altura do peito (DAP) de 6,4 e 4,3 $\mathrm{cm}$, respectivamente, com uma altura média de $5,6 \mathrm{~m}$.

A radiação fotossinteticamente ativa incidente (RFAi) foi medida no sub-bosque do SSP em pleno sol para fins de caracterização das condições luminosas, com o auxílio de um sensor quântico LI-190-1, com banda espectral de 400700 nm, acoplado a um porômetro de Equilíbrio Dinâmico modelo LICOR-LI1600.As leituras foram realizadas a cada quinze dias, entre as 9:00 e 11:00 horas. No sub-bosque, as medidas foram aferidasa um metro de distância das árvores e no topo do dossel do azevém. No pleno sol as medidas foram feitas no topo do dossel do azevém. O pleno sol foi estabelecido como a ausência da espécie florestal, onde a radiação solar não é interceptada pela copa das árvores.

Os valores de interceptação da radiação global foram obtidos de acordo com a seguinte equação proposta por Caron et al., (2012):

$\%$ interceptação $=[100-(R n \times 100 / R t)]$

Onde $\mathrm{Rn}=$ radiação global incidente no interior do dossel; $\mathrm{R} t=$ radiação global incidente no superior do dossel. Simultaneamente foi aferida a temperatura do ar com o uso de termômetro portátil marca Incoterm com precisão de $0,1^{\circ} \mathrm{C}$, em todos os tratamentos.

Para determinar a produtividade da massa de matéria seca (MMS) e o teor de proteína bruta $(\mathrm{PB})$ foram realizados seis cortes com quadro de 0,25 $\mathrm{m}^{2}$, aleatoriamente, em cada uma das unidades experimentais. O primeiro corte ocorreu aos 15 dias após a emergência, quando as plantas apresentavam aproximadamente $20 \mathrm{~cm}$ de estatura. Os demais cortes em intervalos quinzenais (11/07; 26/07; 10/08; 25/08; 09/09/2012), sendo os cinco primeiros no estádio vegetativo e o sexto no estádio reprodutivo.

As amostras coletadas no campo foram evadas a uma estufa de ventilação forçada a 65 ${ }^{\circ} \mathrm{C}$ até massa constante a fim de se determinar MMS da forragem. Na sequência as amostras foram moídas em moinho tipo "Willey" com peneira de 1,0 mm. O teor de proteína bruta $1 \%$ PB) foi determinado pelo método Kjeldahl, por meio da determinação do nitrogênio total, em digestão ácida por ácido sulfúrico (Association of Official Analytical Chemists, 2005). De posse dos valores da porcentagem de nitrogênio, os mesmos foram multiplicados pelo fator 6,25 conforme metodologia de Galvani\& Gaertner (2006).A área foliar(AF; $\mathrm{m}^{2} \mathrm{ha}^{-1}$ ) foi determinada com o auxílio de um Integrador de Área Foliar modelo LI3000.

Os dados foram submetidos à análise estatística, pormeio do programa computacional Statistical Analysis System Learning Edition 8.0 (SAS, 2003).

\section{Resultados e Discussão}

De acordo com a análise de variância, a interação entre sistema de produção $x$ corte demonstrou diferença significativa para a variável MMS. As outras variáveis analisadas, ou seja, teor de $\mathrm{PB}$ e AFdemonstraram diferença em função dos cortes realizados.Os valores de radiação fotossinteticamente ativa incidente (RFAi) e temperatura do ar, no sub-bosque e a pleno sol, além da interceptação de RFA realizada pelas árvores estão descritos na figura 1.

A temperatura média do ar em PS foi de $15,8^{\circ} \mathrm{C}$, já o ambiente gerado pela presença do dossel de árvores resultou em valores médios de $12,8^{\circ} \mathrm{C}$, ou seja, $19 \%$ inferior ao PS (Figura 1). Os extremos de temperatura foram de 6,5 e $22,7^{\circ} \mathrm{C}$ em PS e 5,5 e $17,9^{\circ} \mathrm{C}$ no SSP. A RFAi média durante os meses de execução do experimento foram de $647 \mathrm{\mu gcm}^{2} \mathrm{~s}^{-1}$ em pleno sol,e $248 \mu \mathrm{g} \mathrm{cm}^{2} \mathrm{~s}^{-1}$ no SSP. Estes valores representam uma interceptação média de $54 \%$ da RFApelas árvores de angico.

A Interceptação de RFA em espécies florestais foi relatada por Caron et al. (2012), onde encontraram os seguintes valores nas entrelinhas de plantio: 27,3\% em acácia negra; 56,3\% em bracatinga e $73,8 \%$ nas árvores de eucalipto, independente dos espaçamentos testados 12,0 $\times 1,0 ; 2,0 \times 1,5 ; 3,0 \times 1,0$ e 3,0 m x 1,5 m), ambas as espécies com 1 ano de idade. Caron et al., 
(2014) observaram valores de $85 \%$ paraPinus elliotticom 34 anos de idade, altura média de $25,0 \mathrm{~m}$ e DAP de50,3 cm,sob espaçamento de $8 \times 8 \mathrm{~m}$.

De acordo com Varella et al. (2010), percentuais de transmissão abaixo de $50 \%$ podem causar danos ao crescimento e desenvolvimento de forrageiras de clima temperado. No entanto, para Bernardino \& Garcia (2009), as árvores de um SSP modificam o microclima, através da redução da radiação solar e da relação de espectro de luz, podendo tornar a temperatura mais amena, aumentando a umidade do ar, reduzindo a taxa de evaporação e aumentando a umidade do solo.

O aumento da interceptação de radiação pela copa das árvores a partir dos 45 DAE pode ter sido responsável pela redução significativa da MMS nos cortes correspondentes aos 45, 60 e 90 DAE (Figura 2), no SSP, com relação ao cultivo em PS. Resultados encontrados por Bosi et al. (2014), trabalhando com um sistema silvipastoril de árvores nativas, demonstram que sombreamentos superiores a $39 \%$ afetaram a produtividade da espécie Urochloa decumbens.
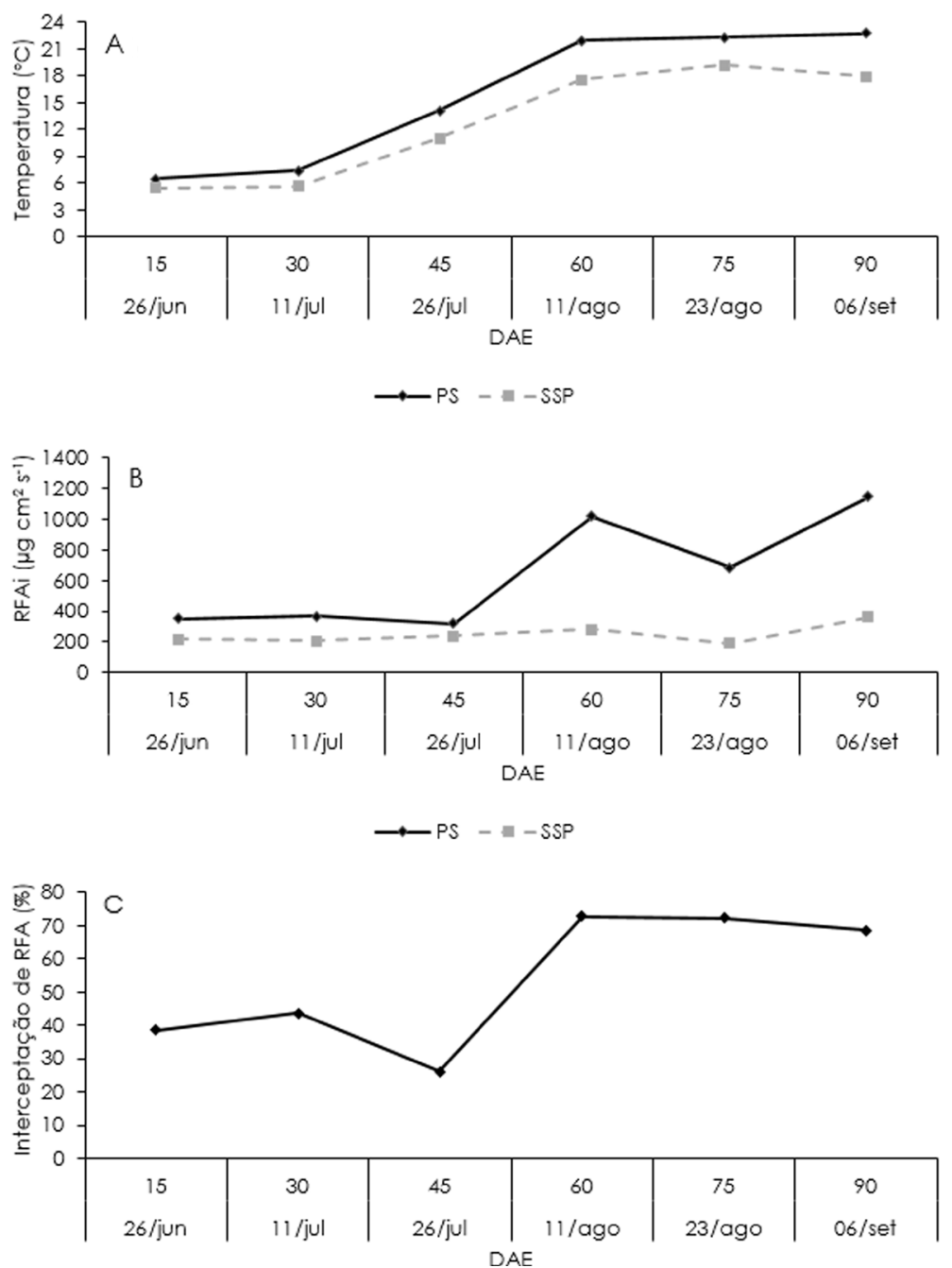

Figura 1. Valores de temperatura média do ar (A), Radiação fotossinteticamente ativa incidente (RFAi) (B) em sistema silvipastoril (SSP) e pleno sol (PS) e interceptação de RFA pela copa das árvores de angico (C), ao longo dos dias após a emergência (DAE) do azevém. Frederico Westphalen - RS, 2014. 

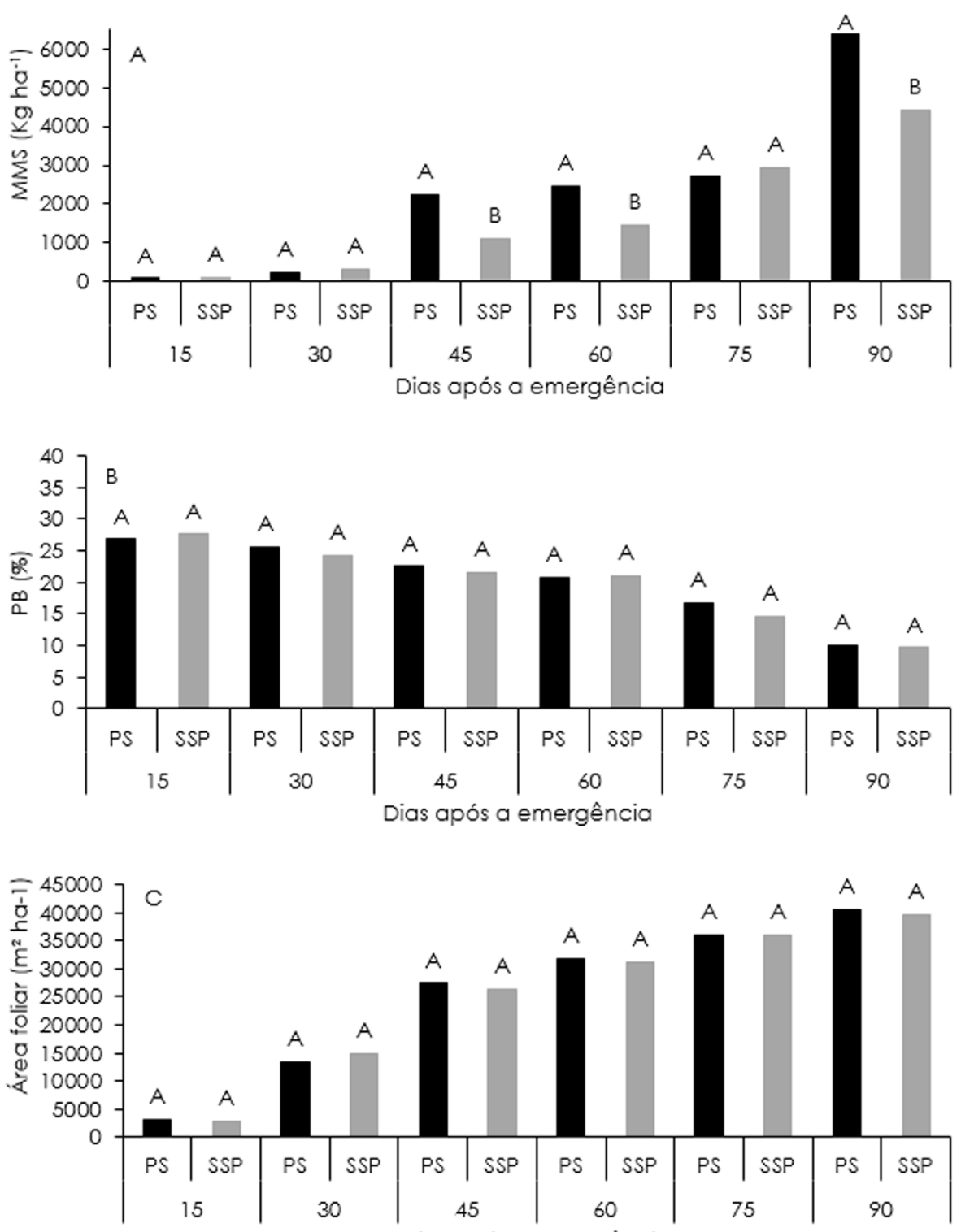

Dias após a emergência

Figura 2. Comparação de médias da Massa de matéria seca (MMS) (A), teor de proteína bruta (PB) (B) e área foliar de azevém (C) cultivado em sistema silvipastoril (SSP) e pleno sol (PS) ao longo dos dias após a emergência (DAE) do azevém. Frederico Westphalen - RS, 2014. *Médias seguidas pela mesma letra, comparando os dois sistemas (PS e SSP) em cada corte, não diferem entre sí, pelo teste de Tukey a $5 \%$ de probabilidade de erro $(p<0,05)$.

Esta redução da MMS do azevém pode ser justificada pelos resultados de Paciullo et al. (2011), ao trabalhar com a espécie Urochloa decumbens cultivada no sub-bosque das espécies arbóreas Acacia mangium, Acacia angustissima,Mimosa artemisiana e Eucalyptus grandis em sistema agrossilvipastoril, afirmando quemecanismos não foram capazes de compensar a redução de radiação e manter a produtividade do pasto, nas condições de sombreamento intenso a até seis metros do renque de árvores. Neste contexto, Baruch \& Guenni (2007) afirmam que níveis de sombreamento acima de $35-40 \%$ podem afetar o crescimento da maioria das gramíneas tropicais, - que pode ser observado, neste trabalho, mesmo esta espécie não sendo tropical.

O azevém é uma espécie de rota de assimilação de dióxido de carbono $\left(\mathrm{CO}_{2}\right)$ do tipo $\mathrm{C}_{3^{\prime}}$ e esses vegetais possuem saturação luminosa na faixa de 25 a $50 \%$ da luz solar plena (Taiz \& Zeiger, 2013), ou seja, são capazes de se adaptar às condições de sombreamento, uma das principais características dos SSP. Dessa maneira, pode-se inferir que durante a execução deste trabalho, a quantidade de RFA transmitida para 
o sub-bosque de angico-vermelho, foi suficiente para que a cultura do azevém completasse seu ciclo de crescimento e desenvolvimento.

A produção média da MMS do azevém foi de 1724 e $2353 \mathrm{Kg} \mathrm{ha}^{-1}$ em SSP e PS, respectivamente. Neste mesmo contexto, Pedroso (2002) propõe que, quando a produção de MMS de azevém atingir entre 1500-1800 kg $\mathrm{ha}^{-1}$, aproximadamente,a pastagem estará estabelecida, pronta para cortes ou receber os animais para pastejo, sem afetar a estrutura das plantas. Estes valores satisfatórios foram encontrados a partir dos 45 e 60 DAE no PS e SSP, respectivamente.

Outro aspecto importante a ser ressaltado é que a menor RFAi no interior do dossel vegetativo devido à interceptação da mesma pela copa das árvores, pode ter sido compensada pelo aumento da radiação difusa neste ambiente, promovendo uma maior eficiência da utilização da radiação solar. Este resultado pode ser complementado por Caron et al. (2014), constatando este comportamento em erva-mate consorciada com Pinus elliottii.

O teor de PB não diferiu estatisticamente entre o SSP e o PS (Figura 2), ou seja, o sombreamento provocado pelas árvores de angico não foi o suficiente para reduzir significativamente o teor de proteína bruta do azevém. Este resultado vai de encontro ao observado por Paciullo et al. (2011), onde o sombreamento promoveu efeito positivo nos teores de PB da espécie Urochloa decumbens cultivada em sub-bosque de Acacia mangium, Acacia angustissima, Mimosa artemisiana e Eucalyptus grandis. Em contrapartida, estes mesmos autores não observaram diferença significativa para as variáveis fibra em detergente neutro (FDN) e fibra em detergente ácido (FDA).

Sousa et al. (2010) destacam que este aumento da PB em local sombreado é verificado principalmente em solos com baixos teores de nitrogênio, uma vez que a deposição de matéria orgânica oriunda da serapilheira das árvores é maior, comparado ao ambiente em pleno sol. A necessidade de nitrogênio da área experimental do presente trabalho foi totalmente suprida de acordo com análise de solo, motivo pelo qual a PB pode não ter demonstrado diferença em nível de significância, entre os dois sistemas de cultivo estudados.Entretanto, resultados semelhantes foram encontrados por Paciullo et al. (2009), não observando diferença na composição químicobromatológica entre o sistema silvipastoril e monocultivo de Urochloa decumbens.

A AF do dossel do azevém não apresentou diferença significativa entre o SSP e pleno sol (Figura 2). Neste contexto Paciullo et al. (2008), trabalhando com Brachiaria decumbens em diferentes graus de sombreamento e épocas do ano, concluíram que o sombreamento não influencia a taxa de aparecimento de folhas e o número de folhas vivas por perfilho, em contrapartida, eleva as taxas de alongamento das folhas e colmo, além do comprimento final das lâminas foliares.

A AF de um dossel vegetativo é a principal responsável pela interceptação da RFA, e essa capacidade de interceptação influencia no crescimento e produção de biomassa pelas plantas. A tendência das plantas, em condições de sombreamento, é aumentar a área foliar para melhorar a captação da pouca luminosidade presente nessas condições, como observado por Paciullo et al. (2007).

Entretanto, os resultados obtidos neste trabalho podem estar relacionados ao fato de que a copa do angico-vermelho, não causou restrição de RFA suficiente para que o azevém expressasse esta característica, a qual é modificada em função da quantidade de MMS produzida e a qualidade nutritiva das forrageiras cultivadas em ambientes sombreados (Garcez Neto et al., 2010).

Os valores de MMS e AF aumentaram com o decorrer do ciclo do azevém (Figura 3), já a PB apresentou comportamento inverso. Ambas as variáveis permitiram o ajuste de uma equação linear nos dois sistemas (no caso da $M M S$ ), entretanto a AF e PB foram desmembradas aos efeitos principais por não ocorrer diferença significativa na interação entre corte e sistema. Não observou-se reduçãoda MS e AF no último corte realizado (90 DAE), uma vez que as plantas de azevém ainda não tinham iniciado o processo de senescência foliar.

A PB variou de 25,2 até $9,8 \%$, dos 15 aos $90 \mathrm{DAE}$, respectivamente. Da mesma forma, 
Pedroso (2002) observou um decréscimo da PB ao longo do ciclo do azevém. Esse resultado pode ser justificado, visto que no estádio vegetativo há maior percentual de folhas em relação a colmos, refletindo nos níveis de nitrogênio da planta $e$, consequentemente, nos teores de PB.

De maneira geral, o cultivo de azevém em sub-bosque de angico-vermelho, pode ser uma alternativa de produção às propriedades rurais do Estado, visto que, o desenvolvimento e qualidade do azevém foram satisfatórios mesmo com o nível de restrição luminosa imposta pela copa da espécie arbórea.
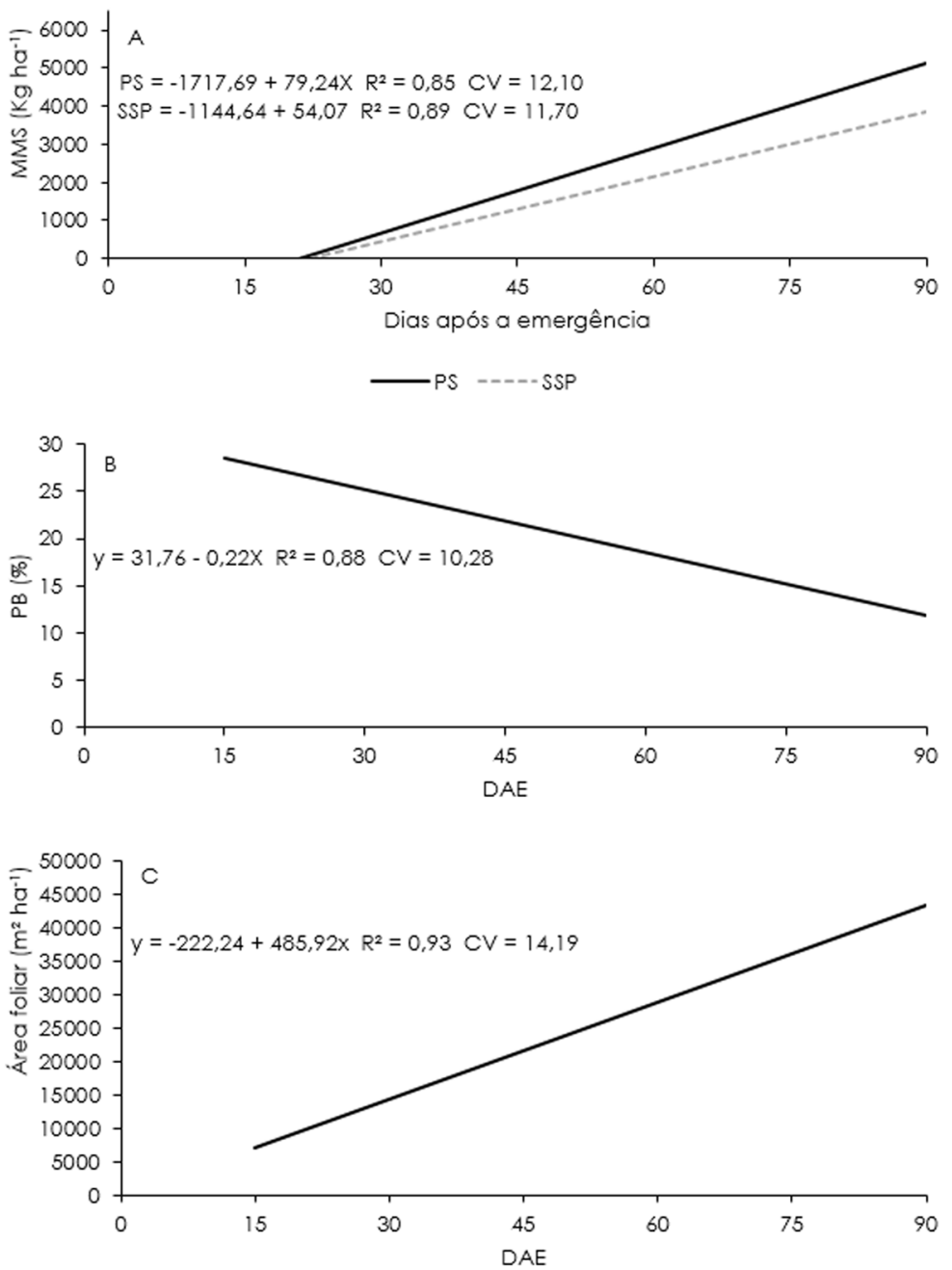

Figura 3. Equações de regressão da massa de matéria seca (MMS) (A), teor de proteína bruta (PB) (B) e área foliar (C) de azevém ao longo dos dias após a emergência (DAE) do azevém. Frederico Westphalen - RS, 2014.

\section{Conclusões}

O desenvolvimento do azevém é influenciado pelo sombreamento, quando cultivado no sub-bosque de angico-vermelho em sistema agrossilvipastoril.

O sombreamento observado no subbosque do angico-vermelho reduz o rendimento da massa de matéria seca do azevém.

O teor de proteína bruta e a área foliar do azevém não são influenciados pela restrição luminosa.

\section{Referências}

Aguiar, M.I. de, Maia, S.M.F., Xavier, F.A. da S., Mendonça, E.S., Araújo Filho, J.A., Oliveira, T.S. de. 2010. Sediment, nutrient and water losses by water erosion under agroforestry systems in the semi-arid region in northeastern Brazil. Agroforestry Systems 79: 277-289.

Association of official analitical chemistry (AOAC). 2005. Official methods of analysis of the Association of Analytical Chemists International. 18. ed. AOAC, Washington, USA, 1583 p.

Balbino, L.C., Cordeiro, L.A.M., Porfírio da Silva, 
V., Moraes, A. de, Martínez, G.B., Alvarenga, R.C., Kichel, A.N., Fontaneli, R.S., Santos, H.P. dos, Franchini, J.C., Galerani, P.R. 2011. Evolução tecnológica e arranjos produtivos de sistemas de integração lavoura-pecuária-floresta no Brasil. Pesquisa Agropecuária Brasileira 46: pi-xii. Prefácio.

Barro, R.S., Saibro, J.C. de, Medeiros, R.B. de, Silva, J.L.S. da, Varella, A.C. 2008. Rendimento de forragem e valor nutritivo de gramíneas anuais de estação fria submetida a sombreamento por Pinus elliottii e ao sol pleno.Revista Brasileira de Zootecnia 37: 1721-1727.

Baruch, Z., Guenni, O. 2007. Irradiance and defoliation effects in three species of the forage grass Brachiaria. Tropical Grasslands 41: 269-276.

Bernardino, F. S., Garcia, R. 2009. Sistemas Silvipastoris. Pesquisa Florestal Brasileira 60: 77-87.

Bosi, C., Pezzopane, J.R.M., Sentelhas, P.C., Santos, P.M., Nicodemo, M.L.F. 2014. Produtividade e características biométricas do capim-braquiária em sistema silvipastoril. Pesquisa Agropecuária Brasileira 49: 449-456.

Caron, B.O., Lamego, F.P., Souza, V.Q. de, Costa, E.C., Eloy, E., Behling, A., Trevisan, R. 2012. Interceptação de radiação luminosa pelo dossel de espécies florestais e sua relação com o manejo de plantas daninhas. Ciência Rural 42: 75-82.

Caron, B.O., Schmidt, D., Manfron, P.A., Behling, A., Eloy, E. Busanello, C. 2014. Eficiência do uso da radiação solar por plantas llex paraguariensis A. ST. HIL. cultivadas sob sombreamento e a pleno sol. Ciência Florestal 24: 257-265.

Comissão de química e fertilidade do solo (CQFS) RS/SC. Manual de adubação e calagem para os estados do Rio Grande do Sul e Santa Catarina. 2004. Porto Alegre: Sociedade Brasileira de Ciência do Solo - Núcleo Regional Sul, 400p.

Cunha, N.G. da, Silveira, R.J.C., Koester, E., Oliveira, L.D. de, Alba, J.M.F., Terres, V.C., Lopes, R.T. 2011. Estudos de Solos do Município de Frederico Westphalen, RS. EMBRAPA. Pelotas, Brasil. Circular Técnica 116.

Galvani, F., Gaertner, E. 2006. Adequação da Metodologia Kjeldahl para determinação de Nitrogênio Total e Proteína Bruta. EMBRAPA. Corumbá, Brasil. Circular Técnica 63.

Garcez Neto, A.F., Garcia, R., Moot, D.J., Gobbi, K.F. 2010. Aclimatação morfológica de forrageiras temperadas a padrões e níveis de sombreamento. Revista Brasileira de Zootecnia 39: $42-50$

Paciullo, D.S.C., Carvalho, C.A.B. de, Aroeira,
L.J.M., Morenz, M.J.F., Lopes, F.C.F, Rossiello, R.O.P. 2007. Morfofisiologia e valor nutritivo do capim-braquiária sob sombreamento natural e a sol pleno. Pesquisa Agropecuária Brasileira 42: 573-579.

Paciullo, D.S.C., Campos, N.R., Gomide, C.A.M., Castro, C.R, Tavela, R.C., Rossiello, R.O.P. 2008. Crescimento de capimbraquiária influenciado pelo grau de sombreamento e pela estação do ano. Pesquisa Agropecuária Brasileira 43: 917923.

Paciullo, D.S.C., Lopes, F.C.F., Malaquias Junior, J.D., Viana Filho, A., Rodriguez, N.M., Morenz, M.J.F., Aroeira, L.J.M. 2009. Características do pasto e desempenho de novilhas em sistema silvipastoril e pastagem de braquiária em monocultivo. Pesquisa Agropecuária Brasileira 44: 1528-1535.

Paciullo, D.S., Gomide, C.A., Castro, C.R., Fernandes, P.B., Müller, M.D., Pires, M.F., Fernandes, E.N., Xavier, D.F. 2011 . Características produtivas e nutricionais do pasto em sistema agrossilvipastoril, conforme a distância das árvores. Pesquisa Agropecuária Brasileira 46: $1173-1186$

Pedroso, C.E.S. 2002. Desempenho e comportamento de ovinos em gestação e lactação nos diferentes estágios fenológicos de azevém anual sob pastejo. 95f. (Dissertação de mestrado) - Universidade Federal do Rio Grande do Sul, Porto Alegre, Brasil.

Sas learning edition. Getting started with the SAS Learning Edition. 2003. Cary, USA. 200 p.

Sousa, L.F., Maurício, R.M., Moreira, G.R., Gonçalves, L.C., Borges, I., Pereira, L.G.R. 2010. Nutritional evaluation of "Braquiarão" grass in association with "Aroeira" trees in a silvopastoral system. Agroforestry Systems 79: 189-199.

Taiz, L., Zeiger, E. 2013. Fisiologia Vegetal. 5. ed. Artmed, Porto Alegre, Brasil 918p.

Varella, A.C., Moot, D.J., Pollock, K.M., Peri, P.L., Lucas, R.J. 2010. Do light and alfalfa responses to cloth and slatted shade represent those measured under an agroforestry system? Agroforestry Systems 20: 1-17.

Wang, Y., Zhang, B., Lin, L., Zepp, H. 2011. Agroforestry system reduces subsurface lateral flow and nitrate loss in Jiangxi Province, China. Agriculture, Ecosystems and Environment 140: 441-453.

Yang, L., Liu, N., Ren, H., Wang, J. 2009. Facilitation by two exotic Acacia: Acacia auriculiformis and Acacia mangium as nurse plants in South China. Forest Ecology and Management 257: 1786-1793. 